\title{
A HERANÇA GRECO-ARABE NA FILOSOFIA DE MAIMÔNIDES: PROFECIA E IMAGINAÇÃO
}

\author{
Rosalie Helena de Souza Pereira* \\ rosaliepereira@uol.com.br
}

RESUMO Para elaborar sua profetologia, Maimônides retoma conceitos relativos às teorias do intelecto de Al-Fārābì e de Avicena, que, por sua vez, se baseiam nas noções sobre a alma de Aristóteles. Dessa perspectiva, a Revelação divina deve ser considerada um fato natural inserido na totalidade da natureza criada por Deus. Compreender a Revelação significa, portanto, compreendê-la a partir do homem, uma vez que o profeta, apesar de se tratar de alguém que se destaca do conjunto da humanidade, é sempre um ser humano, possuidor de uma natureza humana. Desse modo, a doutrina da profecia - central no "Guia dos Perplexos" - é elaborada a partir da natureza humana à luz da filosofia racional greco-árabe. Os falāsifa-filósofos muçulmanos helenizantes - já ensinavam que a profecia é possivel graças a certa perfeição da natureza humana (leia-se intelecto). Esse ensinamento está fundamentado na teoria do intelecto apresentada por Aristóteles em "De Anima” III, 5, 430a 10 et seq. Contudo, para os filósofos de expressão árabe (inclusive Maimônides), a profecia é resultante de certas condições físicas e psíquicas determinadas pelo fluxo necessário das emanações, cuja teoria deriva da "Teologia Pseudo-Aristotélica", um tratado neoplatônico atribuído ao Estagirita que, durante a Idade Média, circulou amplamente nos ambientes filosóficos tanto dos judeus quanto dos muçulmanos. Na cosmovisão neoplatônica adotada por eles, o intelecto do profeta reflete a luz e o conhecimento divino derramado pelo fluxo emanatório (fayd) do

* Pós-doutorado na Pontifícia Universidade Católica de São Paulo (PUC-SP); doutorado em filosofia no IFCH-Unicamp; mestrado em filosofia na FFLCH-USP. Atua como pesquisadora/colaboradora na PUC-SP. Artigo recebido em 27/05/2014 e aprovado em 1\%/08/2014.

KRITERION, Belo Horizonte, $n^{\circ}$ 131, Jun./2015, p. 107-128 
Ser primeiro no mundo celeste, composto pelas dez inteligências separadas, suas almas e esferas. No processo emanatório, a faculdade da imaginação do profeta recebe da última inteligência, o Intelecto Agente, as verdades dos preceitos positivos e culturais da religião, que a imaginação transforma em alegorias e símbolos a serem transmitidos para a humanidade. Maimônides faz da imaginação a pedra de toque de sua profetologia.

Palavras-chave Intelecto, Faculdade da imaginação, Teoria neoplatônica das emanações.

ABSTRACT To elaborate his prophetology, Maimonides uses concepts relating to Al-Fārābi and Avicenna's theories of the intellect which, in turn, are based on Aristotle's notions of the soul. Within this perspective, divine Revelation should be considered a natural fact within the totality of nature created by God. Understanding Revelation therefore means understanding it from a human standpoint, since the prophet-despite being a figure who is set apart from the rest of humanity - is always a human being, with a human nature. Thus, the doctrine of prophecy - central to "The Guide of the Perplexed" is elaborated based on human nature in light of the rational Greco-Arabic philosophy. The falāsifa - the Hellenizing Muslim philosophers - taught that prophecy is possible thanks to certain perfection of the human nature (in other words, the intellect). This teaching is based on the theory of the intellect, as presented by Aristotle in "De Anima" III, 5, 430a 10 et seq. Therefore, for the philosophers of Arabic expression (including Maimonides), prophecy is the result of certain physical and psychic conditions determined by the necessary flow of emanations, whose theory is derived from the "Pseudo-Aristotelian Theology", a Neoplatonic treatise attributed to the Stagyrite which, in the Middle Age, widely circulated in the philosophical milieu, among both Jewish and Muslim. In the Neoplatonic cosmic vision which they adopted, the prophet's intellect reflects the divine light and knowledge overflowing from the emanatory flow (fayd) from the first Being in the celestial world, which is composed of the ten separate intelligences, their souls and their spheres. In the emanatory process, the prophet's faculty of imagination receives from the ultimate intelligence, the Active Intellect, the truths of the positive and cultural precepts of religion, which the imagination transforms into allegories and symbols to be transmitted to humanity. Maimonides makes the imagination the cornerstone of his prophetology.

Keywords Intellect, Faculty of imagination, Neoplatonic theory of emanation. 


\section{Introdução}

Qualquer um que se debruce sobre a filosofia elaborada na Idade Média não pode deixar de notar a estreita correlação entre as filosofias oriundas inicialmente dos ambientes árabe-islâmico e judaico e, mais tarde, do cristão. A intenção de resolver determinados problemas e as soluções levantadas pelos sábios das três comunidades põem em relevo o fato de que pertencem ao "Povo do Livro" ("Ahl al-Kitāb"), como são designadas no Corão. Fundadas na Revelação do Livro - a Torá para os judeus, o Corão para os muçulmanos e os Evangelhos para os cristãos -, essas comunidades, conhecidas como "os três anéis", deixaram um legado de capital valor, cuja influência, direta e indireta, pode ser constatada até em Descartes, que, a despeito de anunciar o rompimento com a tradição aristotélico-tomista, não consegue se desvencilhar completamente das teses recebidas de seus professores jesuítas.

Nesta introdução à questão da profecia em Maimônides, não será abordada a filosofia gerada em ambiente cristão, embora se faça necessário reconhecer e apreciar sua magnitude. ${ }^{1}$ Apresentamos alguns aspectos que foram comuns tanto na filosofia judaica quanto na árabe-islâmica e, em especial, o que se refere à faculdade da imaginação no exercício da profecia. Maimônides reluta em reconhecer sua dívida para com Avicena, o qual é, sem dúvida, fonte de inspiração para muitas doutrinas maimonideanas. Em sua obra filosófica "Guia dos Perplexos", 2 o Rambam não menciona sequer uma vez o filósofo persa; e, em carta dirigida a Ibn Tibbon, declara que "os livros de Avicena, ainda que sejam sutis e difíceis, não são como os de Al-Fārābī”, cuja obra é "plena de sabedoria" (Maimônides, 2003, pp. 43-44). ${ }^{3}$

Nascida em zonas geográficas de cultura predominantemente islâmica, a filosofia judaica foi desmerecida por alguns historiadores que afirmavam ser ela mera cópia da filosofia árabe. Tal opinião, porém, passou a ser desacreditada sobretudo em virtude dos trabalhos de Salomon Munk, que, em 1859, publicou "Mélanges de philosophie juive et arabe". Que a filosofia

1 Ver Wohlman, 1988.

2 Em hebraico: Moré Nevukim. O substantivo moré (masc.) aplica-se tanto àquele que atua como 'guia' espiritual quanto ao mestre intelectual no sentido de docente, professor, instrutor; o título em árabe é Dalālat al-ḩa'irīn; dalālat (fem.) significa "guia, direção, orientação", cf. Maeso (1998, p. 17). Maimônides escreveu a totalidade de suas obras em árabe, exceção feita à sua codificação do Talmud, Mishné Torá (Repetição da Lei), o qual foi redigido em hebraico (cf. Hassoun, 1994, p. 289, nota 3). Ao longo deste artigo, as citações do "Guia dos Perplexos" seguem a tradução espanhola realizada por David Gonzalo Maeso (1998), embora seja citada, em algumas passagens, a tradução inglesa de Friedländer a partir do árabe (Maimônides, 1956).

3 Carta enviada a Shmuel ibn Tibbon em 8 tishri (30 de setembro) de 1199 e reproduzida na tradução italiana de Mauro Zonta. 
judaica seja mera cópia da árabe é opinião que não pode mais ser sustentada, assim como a que afirma que a filosofia árabe é mera reprodução da grega. Ambas as filosofias - a árabe-islâmica e a judaica - são originais a seu modo. Contudo, certas coincidências entre elas são explicáveis, uma vez que as duas comunidades são regidas pelas diretrizes da fé na Revelação divina.

O fator que desencadeou a produção filosófica na Península Ibérica nos séculos XII-XIII foi o ingresso de Aristóteles no Ocidente, inicialmente em vestes neoplatônicas com as obras de Al-Fārābīi (872-950) e de Avicena (Ibn Sīnā) (980-1037) e, depois, por meio dos comentários ao corpus aristotélico feitos por Averróis (Ibn Rushd) (1126-1198), filho nativo de Córdova, a mesma cidade natal do ilustre filósofo judeu Maimônides. Todos eles redigiram suas principais obras em língua árabe. Algumas chegaram até nós em seu original, outras somente em versões latinas - como é o caso das obras de Averróis, cujos originais árabes, em sua maioria, não sobreviveram, restando as traduções para o latim, além de algumas poucas versões para o hebraico. ${ }^{5}$ Das obras de Al-Fārābī e de Avicena que a posteridade recebeu, o Oriente encarregou-se de conservá-las em seu original árabe; sobreviveram também as traduções para o latim de algumas obras de Avicena que foram realizadas na Escola de Toledo, no século XII, e exerceram muita influência no pensamento do Ocidente cristão.

Dois grandes centros de cultura judaica destacaram-se na Espanha islâmica: Córdova e Lucena. Com a queda de Córdova, em poder dos almôadas, a família de Maimônides foi obrigada a fugir de sua cidade natal e exilar-se, de início, em outras cidades da Península e, por fim, a estabelecer-se no Marrocos.

Natural de uma região onde a tradição cultural hebraica estava impregnada da civilização islâmica, Maimônides demonstra ser um grande conhecedor do Kalām, ${ }^{6}$ a teologia racionalista dos muçulmanos, como está patente em sua principal obra, o "Guia dos Perplexos". Sua formação filosófica é derivada dos pensadores de expressão árabe, pois sabemos que seu mestre foi Avempace (Ibn Bājjah) (m. 1139), filósofo de Saragoça que ficou conhecido por seus comentários às obras de Aristóteles - os tratados sobre a alma e o intelecto, e também sobre a ética. Avempace recebeu os ensinamentos das obras de

Termo árabe que tem afinidade, quanto ao sentido, com o grego logos e significa "discurso"; designa o movimento de teologia especulativa que se formou a partir do século VIII, no Oriente Médio, cujo objetivo era explicar, por meio de argumentos racionais, os dados da Escritura. Sobre o Kalām, ver Verza (2007, pp. 149-175). 
Al-Fārābī, marcados pela doutrina intelectualista de caráter neoplatônico, difundida pela "Teologia Pseudo-Aristotélica" em ambiente de língua árabe. Sem dúvida alguma, a visão cosmogônica de Maimônides (Guia II: 12) espelha a doutrina neoplatônica farabiana das emanações, que também foi adotada por Avicena:

[...] Portanto, é evidente que a ação recíproca dos corpos, em virtude de suas formas, prepara as várias espécies de matéria [substância] para receber a ação do que é incorpóreo, isto é, das formas. Os efeitos produzidos pela ação dos incorpóreos $<$ inteligências separadas> [quando houver mudança na combinação dos elementos] não dependem do contato (do agente com o paciente) nem operam a uma distância determinada, $<$ dado não se tratar de um corpo $>.{ }^{8}<$ Essa ação da inteligência separada $>$ é designada "influência" [ou "emanação"] por analogia a uma fonte cuja água flui em todas as direções sem nenhum lado específico que receba ou faça jorrar seu conteúdo, pois rega tudo em volta, o próximo e o distante. De igual modo, o incorpóreo [inteligência], ao receber a força [de onde quer que provenha] e distribuir potência aos outros, não está limitado a um lado ou a uma distância particulares, tampouco ao tempo. Sua ação é contínua e, sempre que um objeto estiver suficientemente preparado, recebe o efeito dessa ação ininterrupta, designada "influência" [ou "emanação"]. ${ }^{9}$ Porque Deus é incorpóreo e, enquanto causa eficiente, tudo é obra Sua, dizemos que o universo foi criado pela divina influência e que todas as mudanças emanam d'Ele. No mesmo sentido, dizemos que Ele é causa da sabedoria que d'Ele emana e se derrama sobre os profetas. (Maimônides, 1956, p. 170; 1998, p. 266)

\title{
A profetologia de Maimônides
}

\author{
Doutrina central no "Guia dos Perplexos", ${ }^{10}$ a profetologia de Maimônides \\ é bastante complexa. O filósofo enumera as condições necessárias para que \\ haja profecia: o profeta deve dispor de intelecção, imaginação e hábitos
}

7 Zimmermann (1986) estudou a atividade do filósofo árabe Al-Kindī (ca. 800-ca. 870) e de seus discípulos em Bagdá durante os califados de Al-Ma'mūn e de Al-Mu'tasim, ambos patronos das traduções de obras gregas (seja do original, seja via o siríaco) para a língua árabe. Quanto às traduções de textos gregos no estudo que consagrou às origens da "Teologia Pseudo-Aristotélica", o estudioso demonstrou que essa obra pertencia inicialmente a um grupo de textos de metafísica que compreendia não apenas textos de Plotino (paráfrases das "Enéadas" IV a VI), mas ainda de Proclo ("Elementos de Teologia") e de Alexandre de Afrodísia, coleção que visava completar a "Metafísica", de Aristóteles, com uma "antologia [...] de teologia clássica" (cf. Zimmermann, 1986, p. 128; cf. D’Ancona Costa, 1995, p. 167). Outra obra de larga circulação entre os árabes foi o "Liber de Causis", cuja doutrina é derivada dos "Elementos de Teologia", de Proclo, também atribuída a Al-Kindī e seu círculo. O compêndio das duas fontes neoplatônicas, a paráfrase árabe das "Enéadas" IV a VI e os "Elementos de Teologia", de Proclo, formam o que se convencionou denominar "Plotiniana Arabica" (cf. D’Ancona Costa, 1995, p. 155 et seq.).

8 [...]: interpolação ou glosa minha; <...>: conforme a tradução espanhola com base no texto hebraico.

9 Árabe: fayḍ; hebraico: shefa'.

10 Cf. L. Strauss (1995, p. 101): "Prophetology is a central part of the doctrine of the "Guide of the Perplexed". 
perfeitos; além disso, deve possuir a virtude da coragem, a capacidade de adivinhação e a capacidade de conduzir os homens. ${ }^{11}$

No estudo aqui proposto, destacamos os dois primeiros requisitos para que alguém se torne profeta. Intelecção e imaginação perfeitas são qualidades cuja origem é possível traçar nas teorias do intelecto da falsafa, ${ }^{12}$ ou melhor, na herança grega que a filosofia de expressão árabe recebeu.

Leo Strauss (1988, pp. 101 et seq.), em seu clássico estudo sobre a fundamentação da Lei na filosofia, apesar de não ter a intenção de fornecer uma exposição completa da doutrina da profecia de Maimônides, guia o leitor pelo labirinto de ideias que compõem a teoria. Caracteriza a posição de Maimônides como um "pensamento medieval das Luzes em matéria de religião", no sentido de ele possuir a "liberdade para filosofar". Contudo, para Maimônides, não se trata de "difundir a luz, de educar as massas no conhecimento racional, de esclarecê-las" (Strauss, 1988, p. 103). As verdades reconhecidas pela razão devem ser mantidas em segredo, seguindo uma tradição filosófica que remonta a Platão: ocultas ao vulgo, as verdades são acessíveis somente a uma elite de sábios. Esse caráter "esotérico" das "Luzes medievais", como escreve Strauss, funda-se no ideal grego da vida contemplativa, na atividade de contemplar (theorein) - explicitada por Aristóteles no final da "Ética Nicomaqueia" (1177a 7) -, que, para os medievais, pressupõe a Revelação. Na busca de sua perfeição, o homem deve viver uma vida dedicada à theoría, à contemplação de seu objeto supremo, a saber, Deus. A Revelação divina é absolutamente necessária ao ser humano, pois ela lhe concede a Lei que o educa no conhecimento das verdades. Enquanto Lei concedida por Deus a um profeta, a Revelação orienta aqueles que são capazes de filosofar, pois ela é o próprio objeto da filosofia. Sua única finalidade é o chamamento à vida contemplativa e à educação que proporciona ao homem aptidão para contemplar. A mediação do profeta é o argumento de base para que a Revelação não seja compreendida como um milagre de Deus, pois, se assim fosse, não poderia ser apreendida pelas faculdades humanas. Para que seja inteiramente compreendida pelos homens, a Revelação deve ser um fato natural inserido na totalidade da natureza criada por Deus. Compreender a Revelação significa, portanto, compreendê-la a partir do homem, uma vez que o profeta, apesar de

11 Cf. Strauss, 1988, p. 101 et seq.

12 Corruptela do grego philosophía, a falsafa concerne à filosofia de cunho grego que se desenvolveu em terras do Islã. Sobre a transmissão da filosofia grega para a árabe, a literatura é bastante vasta; remetemos o leitor para as referências citadas em nosso ensaio: Pereira, 2007a; destacam-se nessa temática os trabalhos de Gutas, 1998; id., 2000; e, certamente, os de Walzer, 1962, que constituem um referencial clássico. 
se tratar de alguém que se destaca do conjunto da humanidade, é sempre um ser humano, possuidor de uma natureza humana. Desse modo, a doutrina da profecia, no "Guia dos Perplexos", é elaborada a partir da natureza humana à luz da filosofia racional greco-árabe.

\section{As fontes da profetologia de Maimônides ${ }^{13}$}

Os falāsifa - filósofos muçulmanos helenizantes - já ensinavam que a profecia é possível graças a certa perfeição da natureza humana (leiase intelecto). Esse ensinamento está fundamentado na teoria do intelecto apresentada por Aristóteles em "De Anima" III.5, 430a 10 et seq.

Al-Fārābī, um dos primeiros representantes da falsafa, desenvolveu sua teoria do intelecto na "Risāla fĩ al- aql" ("Epístola sobre o Intelecto"), mais tarde retomada por Avicena na parte dedicada à alma do "Kitāb alShifā'" ("Livro da Cura"), cuja versão abreviada "Kitāb al-Najāt" ("Livro da Salvação") foi lida pelos sábios judeus medievais em tradução hebraica somente em meados do século XIV. ${ }^{14}$ Foram as obras de Al-Fārābī que os judeus melhor conheceram, pois não só tiveram acesso à tradução hebraica da mencionada "Epístola" como também à de seu célebre "Kitāb al-Siyāsa alMadaniyya" ("Livro da Política", também conhecido por "Livro dos Princípios e dos Seres") ${ }^{15}$ e puderam conferir o pensamento farabiano nos comentários em hebraico dos filósofos judeus que liam e escreviam em árabe. Embora as obras de Al-Fārābī circulassem mais na comunidade dos sábios judeus em virtude de suas traduções para o hebraico, permanece maior a influência de Avicena no pensamento filosófico dos judeus, que liam e escreviam em árabe. Herbert A. Davidson aponta as razões que encobrem essa influência: os primeiros filósofos judeus que adotaram as noções derivadas de Avicena ou a elas se referiram não mencionam o médico-filósofo por seu nome; além disso, o pensamento aviceniano foi amplamente mediado por outros, e suas teorias acabaram por se entrelaçar com as de Al-Fārābī. ${ }^{16}$ Como exemplo podemos citar os filósofos judeus Judah Halevi (ca. 1085-ca. 1140), Abraão ibn Daūd (ca. 1110-ca.1180) e o próprio Maimônides (1135-1204), que liam o árabe e nessa língua escreveram suas obras filosóficas.

13 Sobre as fontes de Maimônides, permanece um marco de referência o estudo introdutório de Shlomo Pines (1963, Vol. I, pp. Ivii-cxxxiv) à sua tradução inglesa do "Guia dos Perplexos".

14 Cf. Davidson, 1992, p. 181.

15 Steinschneider, 1893 apud Davidson, 1992, p. 180, nota 270.

16 Cf. Davidson, 1992, p. 181. 
Judah Halevi apresenta suas ideias no "Livro do Kuzari", ${ }^{17}$ na forma de um diálogo do rei dos Khazares com um filósofo e três teólogos, um cristão, um muçulmano e um judeu, em que cada um deles expõe seu ponto de vista. O filósofo judeu apresenta uma cosmologia e uma teoria do intelecto humano, ambas fundamentadas nas teorias de Al-Fārābī e de Avicena, embora muito do que Halevi expõe sobre essa temática esteja mais próximo das ideias avicenianas. No interior de uma cosmologia neoplatônica de emanações, o intelecto do homem perfeito entra em comunhão com o Intelecto Agente e recebe a ciência verdadeira, livre de dúvidas. Grande parte das noções é de Al-Fārābī, sobretudo proveniente da "Risāla fī al- aql" ("Epístola sobre o Intelecto"), ${ }^{18}$ embora haja alguns traços distintivos de Avicena, como a noção de que as formas dos quatro elementos procedem do Intelecto Agente ou "doador de formas" (lat.: dator formarum; ár.: wāhib al-șuwwar), termo que Halevi emprega igualmente para designar a última inteligência, a que derrama o conhecimento sobre o homem.

No discurso do rabino, quando faz a defesa do judaísmo, Halevi introduz a profecia como prerrogativa de alguém que possui "visão interior" e acrescenta que "é possível que essa visão interior seja a verdadeira clarividência. [...] É possível que essa visão interior seja a faculdade da imaginação submetida ao controle da razão" (1987, p. 74). Apenas os profetas possuem essa capacidade de separar a imaginação (visão interior) das coisas sensíveis, pois, quando veem uma imagem, "eles a descrevem por meio dos atributos materiais tal como a perceberam", e esses atributos são exatos em relação "às exigências da inspiração, da imaginação e das sensações, mas são inexatos em relação à essência que exige a razão" (1987, p. 74-75). Com os exemplos que Halevi oferece para elucidar a visão profética por meio de coisas materiais, podemos inferir que ele antecipa a teoria da analogia de Tomás de Aquino. Escreve: "Em geral, quando a razão considera a essência divina, ela a compara à luz porque esta constitui o mais nobre dos objetos sensíveis e o mais rarefeito, o que envolve, mais que todos os outros, as diversas partes do universo" (1987, p. 76). O paralelismo entre Deus e as coisas materiais não deve ofender, porque é admissível do ponto de vista da razão. "A comparação é a fortiori do ponto de vista da profecia, cuja visão é mais penetrante do que a visão especulativa" (1987, p. 76), pois percebe a região celeste com a visão interior.

17 Foi o tradutor hebraico Judah ben Saul ibn Tibbon (1120-ca. 1190) que deu o título de "Sefer haKuzari" à obra de Halevi. O título original árabe é: "Kitāb al-hujjat wa al-dalīl fī nuṣr al-dīn al-dalīl” ("Livro da Prova e da Argumentação em Defesa da Religião Depreciada"). O nome de Kuzari ou Khozari foi escolhido pelo tradutor hebraico em referência à anedota histórica escolhida por Judah Halevi para expor suas ideias.

18 Cf. Davidson, 1992, p. 183. 
Halevi descreve o universo e o intelecto humano sem, contudo, nomear nenhum filósofo. Apesar de criticar as teorias filosóficas, aceita-as ao incorporar certas noções filosóficas à sua própria argumentação. Ibn Daūd é o primeiro dos filósofos judeus a tomar abertamente emprestado o Aristóteles árabe. Apresenta uma estrutura do universo e uma teoria do intelecto humano em nome de Aristóteles e de filósofos anônimos. Ainda que com certa reserva, aceita as teorias que expõe. Quanto a Maimônides, como já mencionado, em sua concepção do universo, as esferas celestes são movidas por almas inspiradas pelas inteligências (ou anjos). Acima do céu das inteligências que movem as esferas está a Causa Primeira, que traz a primeira inteligência à existência no processo de emanação. A Causa Primeira não pode emanar uma esfera; logo, a tarefa de emanar o mundo da matéria é deixada à primeira inteligência emanada da Causa Primeira. Mantém-se assim o princípio farabiano e aviceniano ex uno non provenit nisi unum, do um provém somente o um. A primeira inteligência emana sua própria esfera celeste, a alma dessa esfera e a segunda inteligência na série. A processão continua até que a esfera da Lua emana a décima inteligência, também chamada de Intelecto Agente ou Ativo. Os seres humanos recebem o fluxo emanatório do Intelecto Agente, que atualiza a potência de seus intelectos individuais. Na trilha da filosofia árabe, Maimônides considera que a matéria é emanada do Intelecto Agente na forma dos quatro elementos (isto é, seus princípios), pois afirma, sem reservas, que "todas" as formas emanam da última inteligência, o que inclui as formas dos quatro elementos. ${ }^{19}$ Todo o fluxo emanatório que desce das esferas se une às potências do mundo sublunar para preparar a matéria a fim de que esta receba sua forma apropriada. Tal como na teoria de Avicena da preparação da matéria, para Maimônides, toda vez que a mistura (mijāz) dos elementos estiver pronta, a matéria recebe a forma apropriada para aquela mistura. $\mathrm{O}$ que produz a forma, porém, é sempre o Intelecto Agente. Portanto, qualquer forma no mundo sublunar possui uma forma incorpórea recebida do Intelecto

19 Maimônides (“Guia dos Perplexos", II: 19") rebate a teoria aristotélica da eternidade do mundo quanto à emanação "necessária" das esferas e se pergunta sobre a diversidade entre os indivíduos de cada espécie que ocorre na matéria - que, segundo Aristóteles, é una, comum a tudo. Para Aristóteles, a diferença ocorre entre os diversos movimentos e posições, e tudo se origina por necessidade física. Para Maimônides, é o desígnio divino a causa da ordem no universo, "sendo necessárias todas as coisas conforme o desígnio de quem as planejou". E acrescenta: "A melhor prova do desenho do universo eu a encontro nos diferentes movimentos das esferas e na posição fixa das estrelas das esferas. Por essa razão, verás que todos os profetas apontam em direção às esferas e às estrelas quando querem provar a existência necessária de um Ser divino". Para Maimônides, a diversidade é resultado da ação de um agente capaz de determiná-la, cuja ação sobre o movimento das esferas resulta na preparação da matéria para receber as formas dos quatro elementos por meio do Intelecto Agente. O agente não podendo ser outro que Deus, a prova aristotélica da eternidade do mundo não se sustenta para o filósofo judeu, que, de acordo com a crença monoteísta, professa a criação ex nihilo. 
Agente, que é a última inteligência a receber o fluxo contínuo e ininterrupto da processão das emanações que atravessa todas as outras inteligências até chegar a ela - o Intelecto Agente que se encarrega de passar as formas para a matéria do mundo sublunar. Quanto à hierarquia das formas, a exposição de Maimônides reflete claramente a teoria de Avicena do dator formarum, ainda que o filósofo judeu cite a "Risāla fī al- aql" ("Epístola sobre o Intelecto"), de Al-Fārābī. ${ }^{20}$

\section{Intelecção e imaginação proféticas em Maimônides}

Maimônides (“Guia",I: 1) apresenta distinção entre dois termos hebraicos, șelem e to'ar, duas palavras que possuem significados distintos quanto às formas que podem ser apreendidas por diferentes operações mentais. ${ }^{21}$ To 'ar designa a "configuração e o aspecto de uma coisa, segundo a opinião vulgar [...] também designativo de uma produção humana" (Maimônides, 1998, p. 67; 1956, p. 13), ao passo que șelem "significa a forma específica, isto é, aquilo que constitui a essência de uma coisa, por meio da qual a coisa é o que é; a realidade que determina o ser da coisa".

Na definição de șelem, reconhecemos a definição de eîdos de Aristóteles em "Metafísica" Z. 7, 1032 b 1-2: "Por forma entendo a essência de cada coisa e a sua substância primeira (eîdos dè légo tò tí ên eînai hekástou kaì tèn próten ousían)". Em geral, nas obras filosóficas de língua árabe, encontramos șūra, que corresponde à "forma"; quanto à expressão tò tì ên eînai (tem o sentido de "o que era antes de ter sido"), traduzida para o latim por quod quid erat esse, resumida pelo vocábulo quidditas do latim tardio, corresponde ao termo árabe māhiyya. Māhiyya (quididade) exprime o que é comum a todos os indivíduos da mesma espécie.

A continuação do texto parece confirmar que șelem (lat.: quidditas; ár.: māhiyya), no homem, diz respeito à sua capacidade intelectiva, ao passo que, nos ídolos, refere-se à ideia que estes representam e pela qual são adorados. O versículo "façamos o homem à nossa imagem (șelem)" (Gênesis 1:26) significa "façamos o homem com capacidade de apreensão intelectiva", sua especificidade essencial (șelem/māhiyya), e não a figura ou forma física (to ’ar/ șūra).

20 Em trabalho anterior (Pereira, 2002), tive a oportunidade de expor com mais detalhes a teoria farabiana das emanações. Segui o percurso de Madkour (1934), o qual demonstrou a filiação de Avicena a Al-Fārābī no que concerne à teoria das emanações. Avicena batizou de "anjos" as inteligências, mas em nada mudou seu conteúdo.

21 Ver Strauss, 1963, Vol. I, p. xxvi. 
Maimônides ("Guia", I: 3) declara que o termo hebraico temuná possui sentido anfíbolo, uma vez que pode ser empregado em três acepções distintas: 1) a forma (configuração e estrutura) de um objeto percebido pelos sentidos sem a intervenção do intelecto; 2) a forma de um objeto impresso na imaginação; 3) a noção verdadeira de alguma coisa apreendida pelo intelecto.

Ao longo de todo o "Guia", Maimônides chama a atenção do leitor para as crenças intelectuais, as apreensões intelectuais, as apreensões da verdadeira realidade das coisas e para as essências das coisas, sobretudo para o conhecimento de Deus. No que concerne à imaginação, Maimônides adverte seu leitor contra a imaginação, o que fica claro no final da obra, quando, ao mencionar a recomendação de Davi a Salomão quanto à busca do conhecimento de Deus, o filósofo afirma que tal exortação se refere à busca das concepções inteligíveis, e não "às criações da imaginação, pois os pensamentos relativos à área da imaginação não se denominam de'á (conhecimento), mas ha-'olá 'al ruhakém, 'o que vem ao vosso espírito"“ (Ezequiel 20:32) (Maimônides, “Guia”, III: 51; 198, p. 536).

Maimônides finaliza o capítulo sobre a natureza do intelecto com a seguinte observação:

Penso que não podes confundir a representação intelectual com a imaginativa, tampouco que haja lugar em tua faculdade da imaginação para comparar essa matéria com as coisas sensíveis, dado que este tratado foi composto para os que filosofam e conhecem o que foi exposto a respeito da alma e de todas as suas faculdades. (Maimônides, 1998, p. 183)

O Rambam também adverte o leitor contra "os apetites da imaginação" (Maimônides, 1998, p. 69) que levaram Adão a ser expulso do Éden.

Já na Introdução, Maimônides esclarece seu leitor sobre o propósito do tratado, isto é, explicar a Torá, em seu autêntico sentido, para os desorientados, perplexos e confusos que, ao renunciarem à razão, permaneceram agarrados às suas "fantasias"22 (Maimônides, 1998, p. 55).

O capítulo 61 da primeira parte é dedicado à polêmica contra os mutakallimūn, ${ }^{23}$ teólogos racionalistas cuja influência sobre os judeus era maior

22 "Fantasias" parece ter o mesmo sentido que o termo grego tà phantásmata, representações da imaginação, conforme Aristóteles em "De Anima" III. 3-4.

23 O termo mutakallimūn (plural de mutakallim) aparece também traduzido por "teólogos dialéticos" e "escolásticos do Islã". Os teólogos "racionalistas" são assim chamados porque consideravam a lógica um instrumento capaz de fortalecer suas doutrinas religiosas nas disputas contra os ataques de pensadores não ortodoxos. 
que a de outras seitas, tal qual o ash 'arismo. ${ }^{24}$ Os mutakallimūn confundiram, segundo Maimônides, as operações da imaginação com as do intelecto. Embora a profecia necessite tanto da imaginação quanto das faculdades racionais, Maimônides critica as opiniões dos legisladores, visionários e adivinhos que se servem apenas da imaginação para presumir conhecimento. ${ }^{25}$

Por que a polêmica contra a imaginação?

Em Maimônides, a imaginação ocupa um lugar central na teoria da profecia elaborada em sua obra mais conhecida, o "Guia dos Perplexos".

Maimônides herdou a antiga concepção grega - reelaborada pelos árabes - da divisão da alma nas partes nutritiva, apetitiva, sensitiva, imaginativa e racional. $^{26}$

No primeiro capítulo do tratado conhecido por "Oito Capítulos", Maimônides apresenta o que, em sua "opinião", são as cinco "partes da alma", embora inicie sua argumentação enfatizando que "a alma do homem é uma somente". Seguindo a filosofia de expressão árabe, as cinco partes da alma são: a nutritiva ou vegetativa (al-gadiyya); a sensitiva ( $a l-h \bar{a} s s a)$; a imaginativa (almutahayīla); a volitiva ou apetitiva (al-nuzū'iyya); e a intelectual ou racional (al-nătiqa). ${ }^{27} \mathrm{~A}$ definição da faculdade imaginativa que o sábio de Córdova expressa está de acordo com a tradição da filosofia greco-árabe:

A parte imaginativa é a capacidade de conservar a impressão de objetos percebidos pelos sentidos, depois que desapareceram das imediações dos sentidos. Algumas impressões são ligadas às outras e algumas são separadas. Portanto, dos objetos percebidos, essa parte acrescenta outras não percebidas e que são impossíveis de apreender. Por exemplo, o homem imagina uma nave de ferro flutuando no ar, ou um ser humano cuja cabeça está nos céus e os pés na terra, ou um animal com mil olhos. A parte imaginativa soma muitas dessas possibilidades e concretiza-as na imaginação. [...] essa faculdade (imaginativa) combina coisas cuja existência é impossível [...]. (Maimônedes, 1992b, pp. 13-14) 28 $^{28}$

24 Escola teológica fundada por Al-Ash'arī (873-935). O ash'arismo foi uma das doutrinas teológicas mais propagadas durante o período do Islã clássico.

25 Cf. Maimônides, "Guia", II: 36; 1998, pp. 334 et seq.

26 Ver Aristóteles, "De Anima" II- III; Maimônides, "Oito Capítulos" I; Wolfson, 1973, Vol. I, pp. 250-314.

27 Para uma exposição desenvolvida sobre as partes da alma em Avicena, ver Pereira (2007b, pp. 344-356); sobre a mesma temática em Aristóteles, Al-Fārābī e Averróis, ver Pereira (2012, pp. 143-186). Sobre as partes da alma em Aristóteles, ver "De Anima" II.3, 414a 25-414b; "De Anima" III.10, 433b 4-5 (cf. Pereira, 2012, p. 278, nota 23). Em "Fușūl Muntaza'a" ("Aforismos Selecionados"), Al-Fārābī começa afirmando que há cinco principais partes (ajzā') e/ou faculdades (quwà) da alma: a nutritiva (al-ġādiyya); a sensitiva (al-ḥāssa); a imaginativa (al-mutahayîa); a apetitiva/desiderativa (al-nuzūíyya); e a racional (al-nāțiqa). A passagem está calcada em Aristóteles, "De Anima" III.9, 432a 29-432b 7, cujos termos gregos equivalentes são: tò threptikón, tò aísthetikón, tò phantastikón, tò orektikón e tò logistikón (cf. Pereira, 2012, p. 149; p. 280, nota 49).

28 Segui a tradução (portuguesa) do hebraico "Shemona Perakim, Hakdama Lemassechet Avot," de Maimônides. 
Ao longo de toda a sua obra, Maimônides insiste em seu projeto de elucidar a tradição da Torá e explicar como essa tradição integra uma racionalidade idêntica à racionalidade filosófica. ${ }^{29}$ Tomadas emprestadas da filosofia, as proposições especulativas ajudam a decidir entre as múltiplas interpretações dos eventos narrados na Sagrada Escritura. Contudo, se a filosofia serve para esclarecer a tradição da Torá, de modo algum pode substituí-la. É sempre na tradição do judaísmo que permanece o quadro em cujo interior se inscreve a busca filosófica. A síntese que Maimônides opera entre a Escritura e a filosofia não é mera redução de uma herança à outra, pois, se a filosofia permite a interpretação da tradição, será sempre a tradição que orientará e imporá os limites às hipóteses do filósofo. Na crítica que faz ao Kalām, Maimônides chega a observar que nada do que afirma discorda dos sábios andaluzes da comunidade judaica que seguiam os ensinamentos dos filósofos sem se oporem aos princípios da religião mosaica ("Guia", I: 71).

Os falāsifa ensinavam que a profecia é uma certa perfeição da natureza humana e que se alguém fosse possuidor dos dons necessários para profetizar não poderia deixar de seguir sua missão profética. Maimônides segue de perto os árabes, porém discorda deles em um ponto: os dons requeridos para alguém se tornar profeta não faziam dele necessariamente profeta, pois Deus pode sempre recusar o dom da profecia a tal homem, conforme Sua vontade; por isso, a escolha divina por determinado indivíduo constitui um milagre, embora o dom da profecia em si não o seja. Aquele que possui os dons necessários não se torna necessariamente um profeta, mas, para que venha a ser profeta, deve necessariamente possuir tais dons, isto é, as condições para profetizar: a perfeição da intelecção, dos hábitos e da imaginação. ${ }^{30}$ Se a Revelação deve comunicar as verdades essenciais por meio de uma atividade contemplativa, teorética, é necessário que o profeta disponha de um conhecimento em ato, ou seja, um conhecimento de acordo com a perfeição de seu intelecto, que se realiza por meio do conhecimento filosófico. O profeta deve ser também filósofo e, como filósofo, deve chegar à perfeição intelectiva. Maimônides segue os falāsifa no que se refere à doutrina aristotélica da atualização da capacidade intelectiva que, para ele, só se realiza por meio do Intelecto Agente, última das inteligências separadas, mas sempre dependendo de Deus. Para o filósofo, basta a capacidade intelectiva. Para o profeta, contudo, o Intelecto Agente

29 Os filósofos medievais árabes, judeus e, depois, os latinos, procuraram sempre conciliar a verdade da fé escritural com a verdade da razão filosófica. Como declarou Averróis (Ibn Rushd) no "Tratado Decisivo" $\S 18$ ("Fașl al-Maqāl”), "a verdade não contradiz a verdade". Essa máxima sintetiza a busca de toda a filosofia medieval.

30 Cf. Maimônides, “Guia”, II: 32; 36. 
deve exercer influência sobre a capacidade imaginativa, além de exercê-la sobre a intelectiva. $\mathrm{O}$ profeta deve comunicar às massas a Palavra divina por meio de imagens, o que lhe impõe possuir a perfeição da imaginação aliada à perfeição intelectiva. Na definição de Maimônides, a profecia é, portanto, um derramamento da emanação de Deus que é processado pelo Intelecto Agente sobre a faculdade da intelecção e sobre a da imaginação ("Guia", II: 36).

Cabe observar que, no "Guia dos Perplexos", ${ }^{31}$ Maimônides concede um grande destaque para a faculdade imaginativa no exercício da profecia. Ao discorrer sobre o papel da imaginação na atividade profética, o Rambam apoia-se na tradição filosófica greco-árabe da divisão da alma em faculdades cognitivas, além de se vincular à síntese neoplatônica herdada dos árabes ${ }^{32}$ no que se refere ao papel exercido pelo Intelecto Agente - última emanação no sistema das processões das inteligências separadas - sobre as faculdades intelectiva e imaginativa do profeta. Conforme já mencionado, na definição de Maimônides, "a profecia é uma emanação de Deus (seja Ele exaltado!), mediante o Intelecto Agente sobre a faculdade intelectiva em primeira instância e, em seguida, sobre a imaginativa" (Maimônides, 1998, pp. 334 et seq.), sendo que tal estado, ainda que "ao alcance de qualquer homem" (p. 335), representa o mais alto grau de percepção do ser humano, embora não seja acessível apenas com o aperfeiçoamento das ações de conduta e com a aquisição do saber especulativo. Não basta, para Maimônides, portanto, que o Intelecto Agente exerça influência sobre o intelecto humano, uma vez que o profeta deve falar às massas e o faz por meio de imagens. O Intelecto Agente, emanação que provém de Deus, deve também exercer influência sobre a imaginação. Para que a profecia se realize, é necessária "a máxima perfeição

31 Em seu estudo "The Internal Senses in Latin, Arabic, and Hebrew Philosophic Texts", Wolfson (1973, pp. 254-255, nota 27) expõe as expressões e termos árabes e hebraicos que Maimônides usa no "Guia dos Perplexos" para os sentidos externos e internos; transcrevemos aqui a transliteração das expressões hebraicas: a) heiseigot gufiot (kohot) mifahlot: apreensões corporais (potências, virtudes) operantes ou atuantes; b) heiseigot murgashot gluiot: apreensões sensíveis manifestas; c) heiseigot gashmiot vhpealiot: apreensões concretas (palpáveis) atuantes; d) heiseigot hushiot nirot: apreensões dos sentidos externos; e) rayon (dimioni): ideia (imaginária); f) mahshavah sihlit: pensamento racional; g) histaflut (ação reflexiva do verbo lehistakel no sentido de receber a conclusão do próprio pensamento): cogitação; h) tafta: intelecto; i) hitbonanut: inteligência ou intelecção. O objetivo de Wolfson, na parte desse estudo dedicada às concepções dos sentidos internos e externos de Ibn Gabirol, Ibn Ezra e Maimônides, é demonstrar que as listas desses três representantes da filosofia medieval hebraica são traduções da classificação de Galeno. Todavia, é preciso frisar que Maimônides usa o termo "imaginação" em um sentido mais amplo, que engloba as funções dos sentidos internos de Avicena: sentido comum, imaginação retentiva, imaginação compositiva humana, imaginação compositiva animal e estimativa (cf. Wolfson, 1973, p. 291). Com a expressão "sentidos internos", os filósofos medievais de língua árabe, hebraica e latina designavam os sentidos captados inicialmente do mundo físico pelos "sentidos externos", visão, audição, tato, olfato e paladar, e transmitidos para os "internos". Todos eles seguiram Aristóteles, "De Anima" III; "De Memoria et Reminiscentia", obras que apresentam a teoria das faculdades da alma do Estagirita.

32 A "Teologia Pseudo-Aristotélica" ou "Teologia Apócrifa" circulou na Idade Média entre árabes e judeus. 
possível da faculdade imaginativa em sua formação primária" (Maimônides, 1998, p. 335). O profeta, cuja faculdade da imaginação está em ato, é capaz de conhecer de modo imediato, sem "premissas e conclusões", tudo o que os outros homens, ainda que tenham seu intelecto atualizado, não são capazes de conhecer. O profeta é, portanto, superior ao filósofo, visto que dispõe de condições que este não possui. Como o profeta dispõe de uma capacidade de conhecimento superior à do filósofo, Maimônides é impelido a afirmar que o filósofo deve seguir o profeta, já que este possui um conhecimento que deriva da combinação da intelecção com a imaginação. Fato curioso, porque, na primeira parte do "Guia dos Perplexos", Maimônides alerta para a compreensão imaginativa da Escritura, uma vez que ela apreende o individual, e não o universal, visto que está presa à matéria, logo não é capaz de apreender as formas. Maimônides chega a afirmar que é preciso se libertar da influência da imaginação para chegar às verdades supremas, pois a imaginação é oposta à intelecção. ${ }^{33}$ Sigamos a argumentação de Maimônides a fim de esclarecer essa aporia.

O desenvolvimento de qualquer faculdade - nesse caso, a imaginação - depende do grau de perfeição do órgão responsável. Fazendo uso de seus conhecimentos médicos, Maimônides associa a constituição física dos órgãos corporais ao melhor ou ao pior desempenho das faculdades. Na primeira parte do "Guia", o filósofo-médico afirma que "uma é a condição de todos os órgãos, tanto externos quanto internos: são instrumentos para as operações da alma. [...] As 'faculdades', sem dúvida alguma, integram-se aos órgãos" (Maimônides, 1998, p. 131). Assim, para ele, a imaginação é função de um órgão físico e opera de acordo com o funcionamento do órgão que a ela está associado.

$\mathrm{Na}$ primeira parte do tratado, Maimônides refere-se às figuras da imaginação como "criadas" (Maimônides, 1998, p. 132). Na segunda parte, reafirma a condição da faculdade imaginativa de ser "criada de início em toda a sua perfeição" (Maimônides, 1998, p. 338) para que o profeta realize seu destino. Nesse sentido, o profeta já está, desde seu nascimento, destinado a profetizar, pois o órgão que abriga sua faculdade imaginativa é perfeito em sua constituição inicial. Assim, no indivíduo destinado a ser Seu mensageiro, Deus cria o órgão da imaginação sem nenhuma imperfeição.

As operações da faculdade imaginativa consistem em conservar a lembrança das coisas sensíveis e combiná-las, assim como é de sua natureza 
reproduzir imagens. Todavia, é somente com o cessar da atividade dos sentidos que sobrevém a inspiração divina, "sua mais alta e nobre atividade", na forma de "sonhos verdadeiros e de profecia", sem que haja uma diferença qualitativa entre ambos, pois "a ação da potência imaginativa durante o sonho é idêntica à da profecia" (Maimônides, 1998, p. 335), exceto se a faculdade imaginativa não tiver alcançado sua perfeição. Maimônides apoia-se na Sagrada Escritura e cita a Palavra divina: "Se há entre vós um profeta, é em visão que Me revelo a ele, é em sonho que lhe falo" (Números 12:6), ${ }^{34}$ explicando que a faculdade imaginativa, em sua potência máxima, é capaz de "ver" o objeto como se este existisse exteriormente, ou seja, percebe o objeto pelos sentidos corporais. $\mathrm{O}$ "Guia" fundamenta a dupla caracterização da profecia - conhecimento na visão ou na palavra transmitida pelo sonho - para estabelecer os diferentes graus de profecia. Maimônides esclarece que aquilo ao qual a faculdade imaginativa se dedica em estado de vigília será o objeto de seu sonho, uma vez que, desse modo, estará preparada para receber a emanação do Intelecto Agente. Desde o nascimento, o cérebro do profeta é composto de matéria pura, é bem-proporcionado, tem condições perfeitas, e seu corpo inteiro está isento de qualquer enfermidade. $\mathrm{O}$ indivíduo apto para receber a Revelação adquire conhecimento e sabedoria desde que sua faculdade intelectiva passe da potência ao ato. Contra os sábios que afirmam que a profecia é "algo inerente à condição humana" (Maimônides, 1998, p. 336), Maimônides rebate que o profeta deve estar "preocupado apenas com o conhecimento de Deus, com a contemplação de suas obras" e com os assuntos "a respeito dos quais é necessário crer" (Maimônides, 1998, p. 336). Deve, além disso, ter conduta moral adequada, afastando-se dos prazeres materiais e das ambições de poder para que sua faculdade imaginativa, desde que atingido o grau supremo de perfeição e estando em plena atividade, possa receber as verdades divinas e a ciência das opiniões verdadeiras no que se refere à conduta dos homens. São três, portanto, as condições enumeradas por Maimônides para que a profecia se realize em determinado indivíduo: "Perfeição da faculdade intelectiva por meio do estudo, da faculdade imaginativa em sua formação inicial" e a conduta "ética derivada do afastamento de todos os prazeres corporais" (Maimônides, 1998, p. 337).

$\mathrm{Na}$ teoria maimonideana, a faculdade imaginativa ocupa um lugar privilegiado em relação às duas outras exigências. No "Guia dos Perplexos", o autor condiciona o perfeito funcionamento dessa faculdade a um estado 
mental isento de paixões, já que, nos momentos de tristeza e de cólera, o profeta é incapaz de profetizar. Em sua argumentação, Maimônides dá os exemplos de Jacó - incapaz de profetizar em virtude da dor originada pela perda de seu filho José - e de Moisés; este, embora o maior de todos os profetas - o único que se viu diante de Ihwh -, não pôde receber a Revelação porque estava magoado com os crimes de idolatria cometidos pela geração que fugiu do Egito. Entretanto, há diferenças nas atividades proféticas: em Moisés, "a imaginativa não intervinha em sua profecia" (Maimônides, 1998, p. 337), pois o Intelecto Agente se derramava sobre ele sem a mediação da imaginação, o que é característico de sua ação profética, pois Moisés recebeu a Lei diretamente de Ihwh e, portanto, sua ação é diversa da dos demais profetas, que falavam por meio de parábolas. Como exemplo da ação da tristeza que perturba a profecia, Maimônides afirma que esta não foi possível durante o cativeiro da Babilônia porque os israelitas, submetidos à escravidão, encontravam-se em estado de grande abatimento. A faculdade imaginativa deixa, portanto, de funcionar quando o povo está submetido à impiedade, à ignorância e à concupiscência de seus senhores, conforme já havia profetizado Amós (8:12): "Andarão errantes de mar em mar e do Norte ao Oriente em busca da palavra de Ihwh, mas não a encontrarão!"; e como está escrito em Lamentações (2:9): "Seu rei e seus príncipes estão entre os gentios, sem Lei, e seus profetas não recebem a visão de Ihwh". Logo, para que se realize, a profecia necessita do auxílio da faculdade imaginativa, uma vez que, sem ela, haverá apenas ciência especulativa, que é própria dos filósofos. ${ }^{35}$

No profeta, o Intelecto Agente, depois de se derramar sobre a faculdade intelectiva, abre-se sobre a faculdade imaginativa ("Guia", II: 36; 37). Esta tem uma função intermediária entre os sentidos e a intelecção pura. Para o homem comum, ela retém as impressões sensíveis e, depois de combiná-las, passa as "imagens" para o intelecto. Na profecia, ocorre o caminho inverso: as verdades inteligíveis são transmitidas para a imaginação e, em seguida, para os sentidos; surgem então sonhos e visões, inicialmente produtos dos órgãos sensíveis. Sob o influxo do intelecto, a imaginação reproduz ou recombina os dados recebidos do mundo sensível por meio dos sentidos. Para que a atividade dos sentidos seja neutralizada na recepção de alguma mensagem divina, o profeta tem visões ou sonhos, à exceção de Moisés, que falou diretamente com Deus. A imaginação produz um deslocamento da atividade intelectual e cria imagens e parábolas cujo sentido simbólico o profeta é capaz de decifrar 
e transmitir para seu povo. Não basta, pois, apenas a apreensão das verdades reveladas: sem a importante função da transmissão, a profecia não se realiza, pois a grande maioria dos profetas tem como missão ensinar e guiar seus conterrâneos.

Como explicar a palavra divina a partir de um ser humano? Maimônides se debruça sobre o estudo da linguagem profética para explicar os antropomorfismos da Bíblia e cita o adágio talmúdico: "A Torá fala o idioma dos homens"36 ("Guia", I: 26). Como o homem comum pode apenas compreender e imaginar o que é expresso em linguagem humana, a profecia deve levar em conta essa limitação humana e dirigir-se à opinião comum. Além do mais, a linguagem profética faz uso de recursos de oratória que devem ser reconhecidos como tais; tanto Isaías quanto os outros profetas se valiam de metáforas e de hipérboles que não deveriam ser compreendidas ao pé da letra, pois, nesse caso, a interpretação da mensagem profética ocasionaria "uma grande confusão de ideias e opiniões errôneas sobre a Divindade ou mesmo a irreligião e a negação dos princípios da Torá" ("Guia", II: 29). O discurso figurativo das Escrituras é necessário em virtude dos segredos e mistérios nelas contidos, cujo verdadeiro sentido apenas aos sábios é permitido o acesso; segredos e mistérios contidos nas Escrituras devem ser resguardados das massas para que não haja interpretações errôneas das verdades reveladas. Há, pois, um discurso exotérico, acessível às massas, e outro esotérico, reservado a um seleto grupo, tradição que remonta a Platão e a Aristóteles. ${ }^{37}$

Como explicar a capacidade profética de Moisés, que não necessita do auxílio da imaginação? Como explicar que a capacidade profética de Moisés é superior à de todos os outros profetas que profetizaram fazendo uso da faculdade imaginativa? Como explicar a superioridade dos outros profetas em relação aos filósofos, apesar de que aqueles se serviram da atividade da imaginação, e os filósofos não? Tanto os filósofos quanto Moisés não fazem uso da imaginação, ao passo que todos os outros profetas sim. Como então explicar a superioridade de Moisés em relação aos outros profetas, e como explicar a superioridade dos profetas em relação aos filósofos? Todos os profetas fazem uso da imaginação, ao passo que Moisés e os filósofos não.

36 Essa declaração de Maimônides é um princípio universalmente admitido por lei natural, inquestionável, evidente por si mesmo, aceito na linguagem das Escrituras e em sua exegese (cf. Maeso in: Maimônides, 1998, p. 94, nota 66).

37 Ver, a propósito, Averróis, 2005. Nessa obra, Averróis declara que, para a massa, o texto sagrado deve ser ensinado por meio da retórica; os teólogos devem restringir-se ao uso da dialética para interpretar o Livro sagrado e somente aos filósofos cabe a demonstração da veracidade do texto revelado, uma vez que só eles dominam as ferramentas da lógica. 
Nas duas pontas estão "o maior de todos os profetas" e "o maior de todos os filósofos"; ambos não fazem uso dessa faculdade que, todavia, é fundamental para os outros profetas, os quais se encontram entre os dois extremos.

Para resolver essa aporia, Maimônides exemplifica que "o maior de todos os filósofos", Aristóteles, conhecia tudo a respeito do mundo sublunar, embora, a respeito do mundo das inteligências separadas, suas opiniões sejam incompreensíveis, uma vez que "não concordam com a ordem do universo, não se sustentam com qualquer razão e tampouco constituem prova convincente" ("Guia", II: 22). ${ }^{38}$ Se Aristóteles, o Filósofo por excelência, não conhece o mundo supralunar, o que dizer dos outros, comuns mortais? Os homens podem conhecer apenas o mundo no qual vivem, que está sob seus olhos e que lhes é familiar. Conhecem apenas o mundo inferior que lhes é acessível. O mundo superior não é acessível ao conhecimento humano, uma vez que os seres humanos estão presos à matéria.

Os conhecimentos mais elevados são mistérios e se revelam esporadicamente a apenas alguns eleitos. Alguns destes vivem em uma noite profundamente escura que, de tempos em tempos, se ilumina como que por relâmpagos. Outros vivem envolvidos por essa luz, e, para eles, a noite é como o dia. Esse é o caso de Moisés. Para os outros profetas, os relâmpagos se sucedem a uma grande distância, e ainda há os que veem a luz do relâmpago apenas uma vez. Quanto aos filósofos, eles vivem nas trevas, jamais iluminadas por relâmpagos; de tempos em tempos, no entanto, recebem uma vaga luz semelhante ao reflexo em uma superfície polida, mas que desaparece em seguida. Enfim, há os que jamais veem luz alguma; são os que constituem as massas ignorantes (Maimônides, 1998, Introdução, pp. 56-57).

Os profetas se distinguiam de Moisés, visto que recebiam a luz do relâmpago apenas de tempos em tempos, isto é, não viviam continuamente na luz. Não dispunham do conhecimento profético sempre que o quisessem. Retomavam suas atividades cotidianas quando o poder profético os abandonava. Moisés, porém, como os anjos, estava sempre preparado para receber a Revelação; profetizava em todas as ocasiões e "não retornava à sua antiga tenda", ou seja, "abstinha-se das gratificações corporais" ao permanecer com "a mente intimamente vinculada ao Onipotente” (Maimônides, 1992a, p. 144).

38 "Toda a exposição de Aristóteles referente ao mundo sublunar possui perfeita coesão; são coisas cuja causa é conhecida, deduzem-se umas das outras, e o lugar que nelas ocupam a sabedoria e a sagaz captação da natureza é evidente e manifesto. Com relação ao mundo celeste, o homem nada alcança [...]" (Maimônides, "Guia”, II: 24; 1998, p. 302). 


\section{Conclusão}

Destas breves considerações a respeito da profetologia de Maimônides, com ênfase no papel da imaginação em relação ao fato profético, podemos concluir que a teoria da profecia está inserida na teoria do conhecimento. Explicar o fenômeno da profecia com as categorias racionais de um esquema conceitual cosmológico e noético aponta para o aspecto epistemológico da teoria. Para os filósofos medievais, era necessário explicar a veracidade da profecia, isto é, a validade cognitiva de seu conteúdo. Tal como na tradição filosófica árabe-islâmica, em Maimônides há uma noção clara e definida do que se constitui como explicação adequada. $\mathrm{O}$ aristotelismo era o paradigma de uma ontologia muito bem definida, cuja demonstração é sempre, a priori, da causa ao efeito. $\mathrm{O}$ conhecimento e seu corolário, a profecia, não podem se desvincular do esquema neoplatônico das emanações das dez inteligências, uma explicação da ordem cosmológica. O intelecto humano possui faculdades que, segundo seu maior ou menor grau de perfeição, recebem, ou não, a Revelação divina. Assim, na ordem antropológica, a verdade profética inserese em um exame racional fundamentado nas noções herdadas sobretudo da noética aristotélica. O profeta, desde o nascimento, possui a capacidade intelectiva para receber a Revelação divina porque ele é portador de órgãos perfeitos. No que concerne à teoria do intelecto, as faculdades da intelecção e da imaginação perfeitas constituem os requisitos necessários para a recepção da mensagem divina, mas esses requisitos não são suficientes para a realização profética. Acima de tudo, permanecem sempre a vontade e a escolha divinas, que são as causas supremas da Revelação profética.

\section{Referências}

AVERRÓIS (IBN RUSHD). "Discurso decisivo (Fașl al-Maqāl)". Tradução de Aida Ramezá Hanania. São Paulo: Martins Fontes, 2005.

D’ANCONA COSTA, C. "Recherches sur le Liber de Causis”. Paris: J. Vrin, 1995.

DAVIDSON, H. A. "Alfarabi, Avicenna, \& Averroes, on Intellect". Oxford: Oxford University Press, 1992.

GUTAS, D. "Greek Thought, Arabic Culture. The Graeco-Arabic Translation Movement in Baghdad and Early 'Abbāsid Society (2nd-4th/8th-10th centuries)". London: Routledge, 1998.

. "Greek Philosophers in the Arabic Tradition". Ashgate: Variorum, 2000.

HASSOUN, J. "Le Prophète, le législateur et le discours du Maître: à propos de l’Épître sur la persécution”. In: Le Colloque de Cordoue, 8, 9, et 10 mai 1992: Ibn Rochd, Maïmonide, Saint Thomas ou la filiation entre foi et raison. Paris: Éditions Climats, 1994. 
JUDAH HALEVI. “Le Livre du Kuzari”. Trad. M. Ventura. 2. ed. Paris: J. Vrin, 1987. (1. ed., 1932).

KRAYE, J.; RYAN, W. F.; SCHMITT, C. B. (org.). "Pseudo-Aristotle in the Middle Ages: The 'Theology' and Other Texts". London: The Warburg Institute, 1986.

MAESO, D. G. "Estudio preliminar". In: Maimônides, 1998. (1. ed., 1994).

MADKOUR, I. "La Place d'al-Fārābī dans la Philosophie Musulmane". Paris: Adrien Maisonneuve, 1934.

MAIMÔNIDES, M. (MOŠE BEN MAIMON). "The Guide for the Perplexed”. Transl. M. Friedländer. New York: Dover Publ., 1956. (1. ed. 1881).

. "Mishné Torá". Trad. R. Yaacov Israel Blumenfeld. O Livro da Sabedoria, As leis fundamentais da Torá. Rio de Janeiro: Imago, 1992a. Cap. VII, p. 93.

. "Os Oito Capítulos". Trad. Alice Frank. São Paulo: Maayanot, 1992b.

. "Guía de Perplejos". Trad. David Gonzalo Maeso. 2. ed. Madrid: Trotta, 1998. (1994).

. "La Guida dei Perplessi”. A cura di Mauro Zonta. Torino: Utet, 2003.

PEREIRA, R. H. de S. “Avicena. A Viagem da Alma (uma leitura gnóstico-hermética de Ḥayy ibn Yaqzān)". São Paulo: Perspectiva, 2002.

. "Bayt al-Hikma e a transmissão da filosofia grega para o mundo islâmico". In: R. H. de S. Pereira (org.), 2007a. pp. 17-62.

. (org.). "Busca do Conhecimento. Ensaios de filosofia medieval no Islã". São Paulo: Paulus, 2007a. 329-377.

. "A concepção de profecia em Avicena (Ibn Sīnā)". In: (org.), 2007b. pp. $2007 b$.

. (org.) "O Islã Clássico: Itinerários de uma Cultura”. São Paulo: Perspectiva, . "Averróis. A Arte de Governar (Uma leitura aristotelizante da República)". São Paulo: Perspectiva, 2012.

PINES, Shlomo. "Translator's Introduction. The Philosophic Sources of the Guide of the Perplexed". In: M. Maimonides. "The Guide of the Perplexed". Vol. 1. Chicago: The University of Chicago Press, 1963. pp. lvii-cxxxiv.

PUIG, J. "Maimónides Esencial. Una filosofia para judíos y gentiles". Madrid: Montesinos, 2011.

STEINSCHNEIDER, M. "Die hebräischen Übersetzungen des Mittlealters und die Juden als Dolmetscher". Berlin: Kommissionsverlag des Bibliographischen Bureaus, 1893.

STRAUSS, Leo. "How to begin to study The Guide of the Perplexed". In: Maimônides, 1963. pp. xi-lvi. Vol. I.

. La Loi fondée sur la philosophie. La doctrine de la prophétie chez Maïmonide et ses sources. In: 1988. pp. 101-142. [Há uma versão (inglesa) do artigo: STRAUSS, Leo. The Philosophic Foundation of the Law: Maimonides' Doctrine of Prophecy and its Sources. In: , 1995. pp. 101-133. Originalmente, o ensaio foi publicado em 1933, na revista Le Monde Oriental, embora tenha sido escrito em 1931 
para ser publicado em Korrespondenzblatt der Akademie für die Wissenschaft des Judentums, de Berlim.

VERZA, T. M. "Kalām: A Escolástica Islâmica". In: R. H. de S. Pereira (org.). 2007b. pp. 149-175.

WALZER, R. “Greek into Arabic. Essays on Islamic Philosophy”. Cambridge (Mass.): Harvard University Press, 1962.

WOHLMAN, A. "Thomas d'Aquin et Maïmonide: un dialogue exemplaire". Paris: Les Éditions du Cerf, 1988.

WOLFSON, H. A. "Studies in the History of Philosophy and Religion". Cambridge (Mass.): Harvard University Press, 1973.

WOLFSON, H. A. "The Internal Senses in Latin, Arabic, and Hebrew Philosophic Texts". In: 1973. pp. 250-314.

ZIMMERMANN, F. W. "The Origins of the So-Called Theology". In: J. Krayne, W. F. Ryan, C. B. Schmitt (org.), 1986. pp. 110-240.

ZONTA, M. "Maimonide". Roma: Carocci Editore, 2011. 